\title{
Sensitivity of Radio-Photoluminescence Glass Dosimeters to Accumulated Doses
}

Dong Wook Kim

Yonsei University College of Medicine

Jiwon Sung

Seoul National University Hospital

Jaeman Son

Seoul National University Hospital

Min-Joo Kim

Yonsei Cancer Center

Han-Back Shin

Yonsei Cancer Center

Yu-Yun Noh

Yonsei Cancer Center

Hojae Kim

Yonsei Cancer Center

Min Cheol Han

Yonsei Cancer Center

Jihun Kim

Yonsei Cancer Center

Su Chul Han

Yonsei Cancer Center

Kyung Hwan Chang

Yonsei Cancer Center

Hojin Kim

Yonsei University College of Medicine

Kwangwoo Park

Yonsei University College of Medicine

Myonggeun Yoon

Korea University

Jinsung Kim

Yonsei University College of Medicine

Dongho Shin ( $\nabla$ dongho@ncc.re.kr)

National Cancer Center 
Research

Keywords: radio-photoluminescence, glass, dose, accumulate, photon

Posted Date: May 19th, 2020

DOI: https://doi.org/10.21203/rs.3.rs-28810/v1

License: (c) (i) This work is licensed under a Creative Commons Attribution 4.0 International License. Read Full License 


\section{Abstract}

Background This study investigated the effect of accumulated doses on radio-photoluminescence glass dosimeters (RPLGDs) from measurements involving mega-voltage photons.

Methods Forty-five commercially available RPLGDs were irradiated to estimate their dose responses. Photon beams of 6,10 , and $15 \mathrm{MV}$ were irradiated onto the RPLGDs inside a phantom, which were divided into five groups with different doses and energies. Groups 1 and 2 were irradiated at 1, 5, 10, 50, and $100 \mathrm{~Gy}$ in a sequential manner; Group 3 was irradiated 10 times with a dose of $10 \mathrm{~Gy}$; and Groups 4 and 5 followed the same method as that of Group 3, but with doses of $50 \mathrm{~Gy}$ and $100 \mathrm{~Gy}$, respectively.

Results For the annealed Group 1, RPLGD exhibited a linearity response with variance within $5 \%$. For the non-annealed Group 2, readings demonstrated hyperlinearity at $6 \mathrm{MV}$ and $10 \mathrm{MV}$, and linearity at $15 \mathrm{MV}$. Following the 100 Gy irradiation, the readings for Group 2 were $118.7 \pm 1.9 \%, 112.2 \pm 2.7 \%$, and $101.5 \pm$ $2.3 \%$ at 6,10 , and $15 \mathrm{MV}$, respectively. For Groups 3,4 , and 5 , the responsiveness of the RPLGDs gradually decreased as the number of repeated irradiations increased. The percentage readings for the 10th beam irradiation with respect to the readings for the primary beam irradiation were $84.6 \pm 1.9 \%, 87.5 \pm 2.4 \%$, and $93.0 \pm 3.0 \%$ at $6 \mathrm{MV}, 10 \mathrm{MV}$, and $15 \mathrm{MV}$, respectively.

Conclusions The non-annealed RPLGD response to dose was hyperlinear for the $6 \mathrm{MV}$ and $10 \mathrm{MV}$ photon beams but not for the $15 \mathrm{MV}$ photon beam. Additionally, the annealed RPLGD exhibited a fading phenomenon when the measurement was repeated several times and demonstrated a relatively large fading effect at low energies than at high energies.

\section{Background}

Radiation therapy, along with surgery and chemotherapy, plays a critical role as a main treatment approach for cancer patients $[1,2]$. Furthermore, radiation therapy trends are shifting from traditional three-dimensional conformal radiation therapy (3DCRT) techniques to complex radiation delivery techniques, such as intensity-modulated radiation therapy (IMRT), volumetric modulated arc therapy (VMAT), and helical tomotherapy (TOMO), all of which deliver more precise and localized dose distributions $[3,4]$. Because radiation therapy techniques have become more complex and sophisticated, the importance of proper quality control (QC) and quality assurance (QA) for precise patient care has increased [5-7], thereby increasing the importance of accurate in vivo and phantom dose measurements.

In vivo measurement is an important procedure for verifying that, during treatment, a radiation dose has irradiated the patient accurately according to the treatment plan. In vivo measurements are performed at several locations, with these measurements requiring high spatial resolution, high sensitivity, and low dose influence, over a broad range of doses. Silicon diodes, Gafchromic films, metal-oxidesemiconductor field-effect transistors (MOSFETs), and thermoluminescence detectors (TLDs) are all currently used as in vivo dosimetric tools [8-14]. These dosimetric sensors each have their own inherent advantages and disadvantages. TLDs have advantages, such as small detector size, good reproducibility, 
and radiation sensitivity, but also have disadvantages in terms of angular dependence, energy dependence, and relatively large workloads in calibration and measurement procedures [15]. In comparison with TLDs, diodes and MOSFETs, have an advantage in terms of eliciting immediate responses, but these detectors have relatively high initial costs, and exhibit fading effects after dose limitations [8]. Meanwhile, external beam therapy 3 (EBT3) film, the representative Gafchromic film that is currently in use, has an advantage in terms of being thin, and also permits two-dimensional dose distribution; however, it has a relatively long saturation time, and exhibits high uncertainty at low doses [10]. In 1999, the optically stimulated luminescence dosimeter (OSLD) was introduced by McKeever et al.; it comprises crystalline aluminum oxide doped with carbon $\left(\mathrm{Al}_{2} \mathrm{O}_{3}: \mathrm{C}\right)$, and is characterized by high radiation sensitivity, good dose linearity, and a low effective atomic number, and does not suffer from fading [16]. Although they suffer signal losses of $1-2 \%$, OSLDs have an advantage in terms of allowing repeat readings, accumulated readings, sensor identification QR codes, having relatively short reading procedures ( $10 \mathrm{~min}$ ), and having simple read outs that use light instead of heat, which reduces the risk of damage to the detectors. With these advantages, the OSLD is rapidly becoming important in the field of in vivo dosimetry [17].

A commercially available radio-photoluminescence glass dosimeter (RPLGD, GD-302M, Asahi Techno Glass Co., Shizuoka, Japan) has been introduced in Japan as an alternative to TLDs. Similar to OSLDs, RPLGDs are advantageous in that they allow repeat readings, accumulated readings, sensor identification numbers, have relatively short reading procedures, and use the same simple read outs as those of OSLDs $[18,19]$. In 2009, Lee et al. presented the dosimetric characteristics and performance of the RPLGD for environmental exposure situations [20]. They found that the RPLGD fading was approximately $1 \%$ within 30 days of being exposed to approximately $0.6,6$, and 20 mGy. Meanwhile, in a later study in 2019, Shehzadi et al. discovered, via a repeatability test, that the obtainable statistical uncertainty of the RPLGD was within 1\% [21]. They estimated the amount of deviation in the RPLGD reading after irradiation with approximately 1, 3, 5, and 9 Gy using a therapy-level Co-60 gamma ray beam. The RPLGD has relatively good reproducibility and exhibits low energy dependence at energies higher than $200 \mathrm{keV}$. Additionally, the rod-shaped RPLGD, which has a round cross section, may have a relatively small incident-beam angular dependence on the orthogonal direction of the sensor. In comparison with TLDs or OSLDs, the RPLGD has the advantage of being easy and safe to use inside the human body, because of its low toxicity and thin rod shape.

In recent years, RPLGDs have become important in the field of in vivo dosimetry. However, no study on the accumulative dose response of RPLGDs has been conducted thus far. Therefore, in this study, we evaluated and reported on the accumulated dose response of RPLGDs for mega-voltage therapeutic X-ray beams.

\section{Methods}

RPLGD 
The commercially available RPLGD used in this study (GD-302M, Asahi Techno Glass Co., Shizuoka, JAPAN) was a colorless and transparent glass rod with a diameter of $0.15 \mathrm{~cm}$ and a length of $0.85 \mathrm{~cm}$. The by-weight composition of the RPLGD was $51.16 \%$ of $0,31.55 \%$ of $\mathrm{P}, 11.00 \%$ of $\mathrm{Na}, 6.12 \%$ of $\mathrm{Al}$, and $0.17 \%$ of $\mathrm{Ag}$ [22]. The density and effective atomic number of RPLGD were $2.61 \mathrm{~g} / \mathrm{cm}^{3}$ and 12.039 , respectively [22]. The RPLGD used had a thin plastic cover that was $0.28 \mathrm{~cm}$ in diameter and $0.13 \mathrm{~cm}$ in length. A dose estimate for the RPLGD in the reader (FGD-1000; Asahi Techno Glass Co., Shizuoka, Japan) was performed via measurement of the stimulated emission of orange light (500-700 nm) from the dosimeter when a 365-nm mono-energetic laser was exposed on the irradiated dosimeter. During dose readout, there were two readout modes, based on dose values: low-dose-range mode (10 $\mu \mathrm{Gy}-10 \mathrm{~Gy})$, and high-dose-range mode (1-500 Gy). In this study, we used the high-dose-range mode. The advantages of the RPLGD, in comparison with the TLD, include its good reproducibility (1\%) and relatively low energy dependency at energies higher than $200 \mathrm{keV}$ [23-25]. Additionally, in comparison with the TLD or OSLD, the RPLGD has a smaller incident-beam-angle dependency and lower toxicity inside the human body [2629]. The RPLGD is comparable to the $\mathrm{Al}_{2} \mathrm{O}_{3}: \mathrm{C}$ OSLD, which is made of a luminescent material similar to that of TLD, but has a different excitation source and uses a different readout technique. The OSLD is not necessary for the heating procedure, but its detector is affected by visible light. A variety of studies have attempted to characterize the dose response of OSLD; the supra-linearity of the dose response has been reported to be above 300 cGy, with angular dependency and relatively low energy dependency, when a clinical mega-voltage photon and electron beam were used [29]. In 2010, Jursinic reported that the OSLD response to dose was supralinear when the detector received accumulative doses, and that a dose response accuracy of $\pm 0.5 \%$ could be achieved if the sensitivity and extent of supra-linearity were established for each OSLD [30].

Experimental measurements

Figure 1 illustrates the experimental setup. Forty-five RPLGDs were irradiated on a $10 \times 10 \mathrm{~cm}^{2}$ open field, using 6, 10, and $15 \mathrm{MV}$ photon beams. The source-to-surface distance (SSD) was $100 \mathrm{~cm}$, and the depths of the detectors were set relative to the dose-maximum depth of energy: $1.5 \mathrm{~cm}(6 \mathrm{MV}), 2.5 \mathrm{~cm}(10 \mathrm{MV})$, and $3.0 \mathrm{~cm}(15 \mathrm{MV})$. A $20-\mathrm{cm}$-thick block of water-equivalent solid phantom was placed behind the detectors to gather the backscatter of radiation. A 1-cm-thick homemade RPLGD phantom was inserted between the build-up phantom and backscatter phantom. Although the phantom was designed to contain up to 42 RPLGDs, in this study, only 3 RPLGDs were inserted at a time into the homemade phantom to be irradiated with radiation. For accurate dose delivery, the monitor unit (MU) value was corrected, considering the output factor of the linear accelerator measured according to TRS-398 [31] and the percentage depth dose (PDD) of the beam data.

For each energy level, five groups were created, wherein each group involved three detectors and its own set of experimental conditions. For most of the groups, except Group 2, the detectors were initialized each time by being annealed at $400{ }^{\circ} \mathrm{C}$ for $1 \mathrm{~h}$ before each irradiation. For Group 2, the annealing process was skipped during the measurements to evaluate the effect of the annealing process. Groups 1 and 2 were irradiated to values of $1 \mathrm{~Gy}, 5 \mathrm{~Gy}, 10 \mathrm{~Gy}, 50 \mathrm{~Gy}$, and then $100 \mathrm{~Gy}$, in order; readings were taken after each 
irradiation to estimate the dose readout for the integral dose, with (Group 1) and without (Group 2) the annealing procedure. For Group 3, the RPLGD reading procedure was performed after irradiation with a dose of approximately $10 \mathrm{~Gy}$. This procedure was repeated 10 times to evaluate the fading effect of RPLGD. For Groups 4 and 5, the RPLGD reading procedure was conducted after irradiation with $50 \mathrm{~Gy}$ (Group 4) and $100 \mathrm{~Gy}$ (Group 5). In the same way as with Group 3, these procedures were repeated 10 times for each group at three different levels of energy: 6, 10, and $15 \mathrm{MV}$.

\section{Results}

Figure 2 depicts the measurement results for Groups 1 (dashed line) and 2 (solid line). For each run with Group 1, the setup was annealed at $400{ }^{\circ} \mathrm{C}$ for $1 \mathrm{~h}$ before each irradiation. The annealing process was skipped for Group 2. Each group was irradiated to 1, 5, 10, 50, and $100 \mathrm{~Gy}$, in order. The energies of the irradiated beam were (a) 6 MV (open circles: annealed; shaded circles: accumulated), (b) 10 MV (open triangles: annealed; shaded triangles: accumulated), and (c) $15 \mathrm{MV}$ (open squares: annealed; shaded squares: accumulated). Figure 2(d) depicts the dose ratios of measurements and irradiation doses. The solid red lines in Figs. 2(a), 2(b), and 2(c) represent the expected values when the reading of RPLGD increases in proportion to the irradiation dose. Group 2 exhibits a hyperlinear response, as depicted in Fig. 2. In Group 1, when the doses were sequentially increased to 1, 5, 10, 50, and 100 Gy over a total of 5 times, the dose response (dashed black line) did not exhibit a significant difference in comparison with the expected value (solid red line); however, in Group 2, the dose response (solid black line) was higher overall. Table 1 presents the percentages of the measured values relative to the irradiation doses for Groups 1 and 2. The top three rows list the results for Group 1, wherein the setup was initialized each time by being annealed at $400{ }^{\circ} \mathrm{C}$ for $1 \mathrm{~h}$ before each irradiation. Meanwhile, the bottom three rows list the results for Group 2, wherein the setup was not annealed. In the case of Group 1, the percentage of the measured value relative to the beam irradiation was estimated to be within $5 \%$, whereas for Group 2, the percentages of the measured values relative to the beam irradiation were $118.7 \pm 1.9 \%$ for $6 \mathrm{MV}, 112.2 \pm$ $2.7 \%$ for $10 \mathrm{MV}$, and $101.5 \pm 2.3 \%$ for $15 \mathrm{MV}$. 
Table 1

Measurement results for Groups 1 and 2

\begin{tabular}{|c|c|c|c|c|c|c|}
\hline \multirow[t]{2}{*}{ Annealing } & \multirow[t]{2}{*}{ Energy (MV) } & \multicolumn{5}{|c|}{ Exposed Dose (Gy) } \\
\hline & & 1 & 5 & 10 & 50 & 100 \\
\hline \multirow{3}{*}{$\begin{array}{l}\text { Yes } \\
\text { (Group 1) }\end{array}$} & 6 & $100.0 \pm 0.5$ & $98.6 \pm 0.4$ & $101.4 \pm 0.3$ & $96.2 \pm 0.3$ & $104.0 \pm 0.3$ \\
\hline & 10 & $100.0 \pm 1.6$ & $99.9 \pm 0.9$ & $102.4 \pm 1.4$ & $97.3 \pm 0.9$ & $104.6 \pm 1.9$ \\
\hline & 15 & $100.0 \pm 1.0$ & $102.7 \pm 1.9$ & $97.0 \pm 1.5$ & $92.9 \pm 2.3$ & $95.0 \pm 2.6$ \\
\hline \multirow{3}{*}{$\begin{array}{l}\text { No } \\
\text { (Group 2) }\end{array}$} & 6 & $100.0 \pm 0.3$ & $99.0 \pm 0.9$ & $102.4 \pm 0.8$ & $98.7 \pm 3.1$ & $118.7 \pm 1.9$ \\
\hline & 10 & $100.0 \pm 0.9$ & $94.8 \pm 0.8$ & $98.9 \pm 0.8$ & $98.1 \pm 0.2$ & $112.2 \pm 2.7$ \\
\hline & 15 & $100.0 \pm 0.7$ & $102.3 \pm 1.0$ & $90.1 \pm 2.4$ & $93.3 \pm 1.4$ & $101.5 \pm 2.3$ \\
\hline \multicolumn{7}{|c|}{$\begin{array}{l}\text { The top three rows list the results for Group } 1 \text {, wherein the setup is initialized each time by being } \\
\text { annealed at } 400^{\circ} \mathrm{C} \text { for } 1 \mathrm{~h} \text { before each irradiation. The bottom three rows list the results for Group } 2 \text {, } \\
\text { wherein the setup is not annealed. The irradiation dose is sequentially increased to } 1,5,10,50 \text {, and } \\
100 \mathrm{~Gy} \text {, over a total of five steps. }\end{array}$} \\
\hline
\end{tabular}

Figure 3 depicts the measurement results for (a) Groups 3, (b) 4, and (c) 5, assuming that the sensors were reused for similar doses over time. In the experiment, wherein the sequence of initialization, beam irradiation, and reading was repeated 10 times, the responsiveness of the RPLGD gradually decreased as the number of repetitions increased. Table 2 presents the measurement results with respect to the number of irradiations, from 1 to 10 times. Each group was irradiated at doses of 10,50, and $100 \mathrm{~Gy}$, with three different energies, namely, 6,10 , and $15 \mathrm{MV}$. The values are normalized percentages with respect to the 1 st measurement values. The measurement results after 10 repeated beam irradiations were $84.6 \pm 1.9 \%$, $87.5 \pm 2.4 \%$, and $93.0 \pm 3.0 \%$ at $6 \mathrm{MV}, 10 \mathrm{MV}$, and $15 \mathrm{MV}$, respectively. 
Table 2

Measurement results for 10 irradiations for evaluating the fading effect of RPLGD

\begin{tabular}{|c|c|c|c|c|c|c|c|c|c|c|c|}
\hline \multirow{2}{*}{$\begin{array}{l}\text { Energy } \\
\text { (MV) }\end{array}$} & \multirow{2}{*}{$\begin{array}{l}\text { Dose } \\
\text { (Gy) }\end{array}$} & \multicolumn{10}{|c|}{ Sequence } \\
\hline & & 1 & 2 & 3 & 4 & 5 & 6 & 7 & 8 & 9 & 10 \\
\hline \multirow[t]{6}{*}{6} & 10 & 100.0 & 97.3 & 97.6 & 96.5 & 102.0 & 96.0 & 90.4 & 87.6 & 86.1 & 85.9 \\
\hline & & \pm 0.0 & \pm 1.2 & $\frac{ \pm}{2.0}$ & $\begin{array}{l} \pm \\
0.9\end{array}$ & \pm 1.8 & $\stackrel{ \pm}{2.4}$ & $\frac{ \pm}{1.4}$ & $\frac{ \pm}{1.9}$ & $\stackrel{ \pm}{1.0}$ & $\stackrel{ \pm}{2.1}$ \\
\hline & 50 & 100.0 & 96.6 & 96.9 & 94.9 & 98.2 & 95.1 & 92.6 & 85.8 & 85.7 & 83.5 \\
\hline & & \pm 0.0 & \pm 0.5 & $\begin{array}{l} \pm \\
0.7\end{array}$ & $\begin{array}{l} \pm \\
0.4\end{array}$ & \pm 0.5 & $\stackrel{ \pm}{0.6}$ & $\frac{ \pm}{1.7}$ & $\begin{array}{l} \pm \\
0.8\end{array}$ & $\stackrel{ \pm}{2.0}$ & $\stackrel{ \pm}{1.0}$ \\
\hline & 100 & 100.0 & 94.6 & 95.8 & 94.9 & 97.2 & 92.3 & 88.1 & 85.7 & 82.6 & 84.4 \\
\hline & & \pm 0.0 & \pm 1.6 & $\frac{ \pm}{1.5}$ & $\stackrel{ \pm}{0.8}$ & \pm 1.9 & $\stackrel{ \pm}{2.4}$ & $\frac{ \pm}{1.7}$ & $\frac{ \pm}{2} .8$ & $\stackrel{ \pm}{2.1}$ & $\stackrel{ \pm}{1.8}$ \\
\hline \multirow[t]{6}{*}{10} & 10 & 100.0 & 100.4 & 98.8 & 98.4 & 99.4 & 91.3 & 98.1 & 90.1 & 88.5 & 88.2 \\
\hline & & \pm 0.0 & \pm 1.0 & $\begin{array}{l} \pm \\
0.6\end{array}$ & $\begin{array}{l} \pm \\
0.7\end{array}$ & \pm 2.2 & $\stackrel{ \pm}{0.5}$ & $\frac{ \pm}{2.0}$ & $\stackrel{ \pm}{1.9}$ & $\stackrel{ \pm}{2.5}$ & $\stackrel{ \pm}{2.4}$ \\
\hline & 50 & 100.0 & 100.3 & 98.9 & 98.4 & 100.1 & 94.7 & 99.0 & 90.3 & 89.2 & 89.0 \\
\hline & & \pm 0.0 & \pm 1.5 & $\begin{array}{l} \pm \\
0.7\end{array}$ & $\begin{array}{l} \pm \\
0.9\end{array}$ & \pm 0.5 & $\stackrel{ \pm}{1.0}$ & $\begin{array}{l} \pm \\
0.9\end{array}$ & $\begin{array}{l} \pm \\
0.3\end{array}$ & $\begin{array}{l} \pm \\
0.5\end{array}$ & $\stackrel{ \pm}{1.1}$ \\
\hline & 100 & 100.0 & 97.6 & 96.0 & 95.7 & 97.7 & 95.7 & 90.7 & 88.3 & 85.5 & 85.4 \\
\hline & & \pm 0.0 & \pm 1.7 & $\stackrel{ \pm}{2.5}$ & $\begin{array}{l} \pm \\
0.3\end{array}$ & \pm 0.9 & $\stackrel{ \pm}{0.9}$ & $\begin{array}{l} \pm \\
0.7\end{array}$ & $\stackrel{ \pm}{1.1}$ & $\begin{array}{l} \pm \\
0.1\end{array}$ & $\stackrel{ \pm}{1.7}$ \\
\hline \multirow[t]{6}{*}{15} & 10 & 100.0 & 100.1 & 96.9 & 91.4 & 90.3 & 93.1 & 98.2 & 93.4 & 92.8 & 92.1 \\
\hline & & \pm 0.0 & \pm 1.8 & $\stackrel{ \pm}{4}_{4.0}$ & $\stackrel{ \pm}{4.0}$ & \pm 1.5 & $\stackrel{ \pm}{2.9}$ & $\frac{ \pm}{2.8}$ & $\frac{ \pm}{3.4}$ & $\frac{ \pm}{2.7}$ & $\stackrel{ \pm}{1.8}$ \\
\hline & 50 & 100.0 & 99.7 & 98.1 & 95.5 & 95.2 & 95.5 & 97.0 & 96.7 & 94.2 & 95.1 \\
\hline & & \pm 0.0 & \pm 0.7 & $\begin{array}{l} \pm \\
0.9\end{array}$ & $\stackrel{ \pm}{0.4}$ & \pm 0.5 & $\stackrel{ \pm}{1.3}$ & $\frac{ \pm}{1.4}$ & $\stackrel{ \pm}{0.5}$ & $\frac{ \pm}{2.1}$ & $\stackrel{ \pm}{1.7}$ \\
\hline & 100 & 100.0 & 98.4 & 98.5 & 94.4 & 94.9 & 94.5 & 92.8 & 96.6 & 93.1 & 92.0 \\
\hline & & \pm 0.0 & \pm 1.6 & $\frac{ \pm}{1.1}$ & $\stackrel{ \pm}{1.5}$ & \pm 0.7 & $\frac{ \pm}{1.6}$ & $\frac{ \pm}{1.7}$ & $\frac{ \pm}{2.1}$ & $\frac{ \pm}{2.0}$ & $\stackrel{ \pm}{3.9}$ \\
\hline
\end{tabular}


Figure 2 depicts that, up to a 50 Gy irradiation, the dose response was not significantly different; however, after a $100 \mathrm{~Gy}$ irradiation, the response in Group 2 increased to $118 \%$. Thus, when measured with the RPLGD, the dosimeter response was not proportional to the irradiation dose and exhibited a hyperlinear pattern that resulted in a slightly higher reading when the setup was cumulatively irradiated without annealing. Additionally, the hyperlinear response of Group 2 did not appear significantly until the setup was irradiated with $50 \mathrm{~Gy}$, but exhibited a significant increase in dose response by up to $118 \%$ when the setup was irradiated with $100 \mathrm{~Gy}$. As presented in Table 1, in the case of Group 1, the percentage of the measured value relative to beam irradiation was estimated to be within $5 \%$, whereas for Group 2, the percentages of the measured values relative to beam irradiation were $118.7 \pm 1.9 \%$ for $6 \mathrm{MV}, 112.2 \pm 2.7 \%$ for $10 \mathrm{MV}$, and $101.5 \pm 2.3 \%$ for $15 \mathrm{MV}$.

Furthermore, the changing effect in dose response due to dose accumulation was also dependent on beam energy. As shown in Fig. 2 and Table 1, the data for the $15 \mathrm{MV}$ beam dose do not exhibit hyperlinearity in both the annealed (Group 1) and accumulated (Group 2) cases. Table 3 presents the fitting results for the annealed (Group 1) and accumulated (Group 2) cases via the least square function and quadratic polynomial function. Data fitting was performed using SigmaPlot (Sigmaplot version 14.0, Systate Software, Inc. San Jose, CA 95131, USA) with the Shapiro-Wilk fitting evaluation tool. For the annealed (Group 1) case, the P values obtained from the Shapiro-Wilk test for most of the data were greater than 0.05 with the least square function. For the non-annealed (Group 2) case, the P values for the $6 \mathrm{MV}$ and $10 \mathrm{MV}$ data were lesser than 0.05 with the least square function. For the $15 \mathrm{MV}$ non-annealed data (Group 2), the $P$ value from the Shapiro-Wilk test was 0.6429 . 
Table 3

Fitting results for Groups 1 and 2

\begin{tabular}{|c|c|c|c|c|c|c|c|c|}
\hline $\begin{array}{l}\text { Energy } \\
\text { (MV) }\end{array}$ & $\begin{array}{l}\text { Annealing } \\
\text { Process }\end{array}$ & $\begin{array}{l}\text { Fitting } \\
\text { Function }\end{array}$ & $y_{0}$ & $\mathbf{a}$ & b & $\mathrm{R}^{2}$ & $\begin{array}{l}\text { STD } \\
\text { Error }\end{array}$ & $\begin{array}{l}\text { Shapiro- } \\
\text { Wilk (P> } \\
0.05)\end{array}$ \\
\hline \multirow[t]{4}{*}{6} & Yes & $\begin{array}{l}\text { Least } \\
\text { square }\end{array}$ & 0.4382 & 1.0000 & - & 0.9975 & 2.1775 & 0.1731 \\
\hline & & 2nd Poly & 0.5653 & 0.8758 & 0.0016 & 0.9998 & 0.5829 & 0.5182 \\
\hline & No & $\begin{array}{l}\text { Least } \\
\text { square }\end{array}$ & 3.6384 & 1.0000 & - & 0.9713 & 8.4095 & 0.0005 \\
\hline & & 2nd Poly & 1.0176 & 0.7714 & 0.0040 & 0.9996 & 0.9937 & 0.6804 \\
\hline \multirow[t]{4}{*}{10} & Yes & $\begin{array}{l}\text { Least } \\
\text { square }\end{array}$ & 0.6996 & 1.0000 & - & 0.9973 & 2.2882 & 0.0570 \\
\hline & & 2nd Poly & 0.5413 & 0.8913 & 0.0015 & 0.9998 & 0.5630 & 0.6158 \\
\hline & No & $\begin{array}{l}\text { Least } \\
\text { square }\end{array}$ & 2.1819 & 1.0000 & - & 0.9857 & 5.639 & 0.0010 \\
\hline & & 2nd Poly & 0.6074 & 0.8298 & 0.0029 & 0.9998 & 0.6088 & 0.4727 \\
\hline \multirow[t]{4}{*}{15} & Yes & $\begin{array}{l}\text { Least } \\
\text { square }\end{array}$ & -1.1926 & 1.0000 & - & 0.9944 & 2.9737 & 0.0031 \\
\hline & & 2nd Poly & 0.4383 & 0.8989 & 0.0005 & 0.9999 & 0.327 & 0.0607 \\
\hline & No & $\begin{array}{l}\text { Least } \\
\text { square }\end{array}$ & -0.5494 & 1.0000 & - & 0.9982 & 1.8029 & 0.6429 \\
\hline & & 2nd Poly & 0.4868 & 0.8382 & 0.0017 & 0.9999 & 0.3636 & 0.5408 \\
\hline $\begin{array}{l}\text { Group } \\
2 \text { is not } \\
\text { total of } \\
\text { functio }\end{array}$ & $\begin{array}{l}\text { tialized } \\
\text { aled. Th } \\
\text { teps. Th }\end{array}$ & $\begin{array}{l}\text { time via a } \\
\text { diation do } \\
\text { st squares } \\
\text { ment resu }\end{array}$ & $\begin{array}{l}\text { ealing at } \\
\text { is seque } \\
\text { nction at }\end{array}$ & $\begin{array}{l}0^{\circ} \mathrm{C} \text { fol } \\
\text { lly incr } \\
\text { fuadrat }\end{array}$ & $\begin{array}{l}\text { befor } \\
\text { ed to } 1 \\
\text { olynor }\end{array}$ & $\begin{array}{l}\text { ch irra } \\
10,50, \\
\text { functi }\end{array}$ & $\begin{array}{l}\text { tion, wh } \\
\text { d } 100 \mathrm{G} \\
\text { are usec }\end{array}$ & $\begin{array}{l}\text { as Group } \\
\text { ver a } \\
\text { s fitting }\end{array}$ \\
\hline
\end{tabular}


Table 4

Fitting results for fading slope, intercept, and error obtained via least square fit

\begin{tabular}{|c|c|c|c|c|c|c|c|c|c|}
\hline \multirow{2}{*}{$\begin{array}{l}\begin{array}{l}\text { Dose } \\
\text { (Gy) }\end{array} \\
\begin{array}{l}\text { Energy } \\
\text { (MV) }\end{array}\end{array}$} & \multicolumn{3}{|c|}{10 (Group 3) } & \multicolumn{3}{|c|}{50 (Group 4) } & \multicolumn{3}{|c|}{100 (Group 5) } \\
\hline & Slope & Intercept & Error & Slope & Intercept & Error & Slope & Intercept & Error \\
\hline 6 & -1.723 & 102.698 & 0.661 & -1.879 & 102.497 & 0.768 & -2.047 & 102.243 & 0.768 \\
\hline 10 & -1.663 & 103.840 & 0.686 & -1.439 & 103.342 & 0.716 & -1.521 & 100.688 & 0.831 \\
\hline 15 & -0.682 & 98.866 & 0.056 & -0.497 & 99.661 & 0.586 & -0.761 & 99.608 & 0.605 \\
\hline \multicolumn{10}{|c|}{$\begin{array}{l}\text { These results are for three values of energy and three values of dose. Groups } 3,4 \text {, and } 5 \text { are irradiated } \\
\text { with doses of } 10,50 \text {, and } 100 \mathrm{~Gy} \text {, respectively. Each group is irradiated at three different energies }(6 \text {, } \\
10 \text {, and } 15 \mathrm{MV}) \text {. }\end{array}$} \\
\hline
\end{tabular}

The fitting results also demonstrated that the dose response for the annealed case (Group 1) was linear with respect to the irradiation dose. For the non-annealed case (Group 2), the $6 \mathrm{MV}$ and $10 \mathrm{MV}$ data exhibited a hyperlinear dose response, whereas the $15 \mathrm{MV}$ data exhibited a linear response. Therefore, when measurements are being conducted using RPLGD, particularly in the case of measurements at low energies with high doses, it is suggested that the annealing process be performed each time to reduce errors due to dose accumulation. In contrast, it is possible to correct the data response by considering the hyperlinearity of RPLGD through the use of a fitting parameter. In the results for Groups 1 and 2, the dispersion between the measuring elements was measured to be within $3 \%$. Therefore, given that, the difference between the sensors is small in the measurement, it is possible to correct the read dose value via acquisition of factors related to the cumulative dose response of each device with respect to energy, rather than via initialization of the sensor every time before measurement.

Figure 3 depicts that the responsiveness of the RPLGD gradually decreases to approximately $-15 \%$ as the number of repetitions increases. This fading phenomenon is more prominent at lower energies than at higher energies. However, a significant relationship does not appear to exist between the magnitude of the dose irradiated to the device and the fading effect. As presented in Table 2, the fading slope obtained via a least square fit was largest at $6 \mathrm{MV}$ and smallest at $15 \mathrm{MV}$. The measurement results after 10 repeated beam irradiations were $84.6 \pm 1.9 \%, 87.5 \pm 2.4 \%$, and $93.0 \pm 3.0 \%$, at $6 \mathrm{MV}, 10 \mathrm{MV}$, and $15 \mathrm{MV}$, respectively. However, until the fifth measurement in the overall measurement process, the fading effect was insignificant, being within $5 \%$. Therefore, if possible, recalibrating the RPLGD after five uses is necessary to correct the sensitivity degradation due to the fading effect. Although correcting the measured value by considering the effect of fading on each RPLGD is possible at each energy level, in this case, the similarity of the dose responses among the RPLGDs should be evaluated.

In this study, measurements were performed using only three devices in each group; however, more detailed results can be obtained through the use of a greater number of glass dosimeters to reduce the statistical uncertainty in the near future. 


\section{Conclusions}

The non-annealed RPLGD response to dose was determined to be hyperlinear for the $6 \mathrm{MV}$ and $10 \mathrm{MV}$ photon beams but not for the $15 \mathrm{MV}$ photon beam. This response was also found to change according to the amount of accumulated dose delivered to the RPLGD. Additionally, the annealed RPLGD was observed to exhibit a fading phenomenon when the measurement was repeated several times, and the fading effect was relatively significant at low energies in comparison with high energies. In this study, measurements were performed using only three devices in each group; however, more detailed results and predictions for the responses can be obtained in the near future through the use of a greater number of glass dosimeters to reduce statistical uncertainty. Moreover, after up to five repeated uses, the calibration of each device needs to be performed to reduce the uncertainty caused by the fading effect. Furthermore, we suggest that the annealing procedure should be performed before each measurement.

\section{Abbreviations}

3DCRT

three-dimensional conformal radiation therapy

EBT3

external beam therapy 3

IMRT

intensity-modulated radiation therapy

MOSFET

metal-oxide-semiconductor field-effect transistor

MU

monitor unit

OSLD

optically stimulated luminescence dosimeter

PDD

percentage depth dose

QA

quality assurance

QC

quality control

RPLGD

radio-photoluminescence glass dosimeters

SSD

source-to-surface distance

TLD

thermoluminescence detectors

TOMO 
tomotherapy

VMAT

volumetric modulated arc therapy

\section{Declarations}

Ethics approval and consent to participate

Not applicable

Consent for publication

Not applicable

Availability of data and materials

The datasets used and/or analyzed during the current study are available from the corresponding author on reasonable request.

Competing interests

The authors declare that they have no competing interests.

Funding

This work was supported by the general researcher program (NRF- 2018R1D1A1B07050217) and the nuclear safety research program (No. 2003013-0120-CG100) through the Korea Foundation of Nuclear Safety (KOFONS), using the financial resource granted by the Nuclear Safety and Security Commission (NSSC), Republic of Korea.

Authors' contributions

DWK, DS, and JK designed and wrote the final version of the manuscript for this research. JWS, JMS, and MY wrote the first version of the manuscript. HBS, MJK, YYN, HK, MCH, SCH, and KHJ participated in the measurements. HK, and KP participated in the detector calibrations. All authors read and approved the final manuscript.

Acknowledgments

Not applicable

\section{References}

1. Ingle JN, Parulekar WR. Extending Adjuvant Aromatase-Inhibitor Therapy to 10 Years. N Engl J Med. 2016;375(16):1591. 
2. Thompson MK, Poortmans P, Chalmers AJ, Faivre-Finn C, Hall E, Huddart RA, Lievens Y, SebagMontefiore $\mathrm{D}$, Coles CE. Practice-changing radiation therapy trials for the treatment of cancer: where are we 150 years after the birth of Marie Curie? Br J Cancer. 2018;119(4):389-407.

3. Cho B. Intensity-modulated radiation therapy: a review with a physics perspective. Radiat Oncol J. 2018;36(1):1-10.

4. Hatano K, Tohyama N, Kodama T, Okabe N, Sakai M, Konoeda K. Current status of intensitymodulated radiation therapy for prostate cancer: History, clinical results and future directions. Int $\mathrm{J}$ Urol. 2019;26(8):775-84.

5. Azcona JD, Siochi RA, Azinovic I. Quality assurance in IMRT: importance of the transmission through the jaws for an accurate calculation of absolute doses and relative distributions. Med Phys. 2002;29(3):269-74.

6. Steiniger B, Berger R, Eilzer S, Kornhuber C, Lorenz K, Peil T, Reiffenstuhl C, Schilz J, Schroder D, Schwedas $M$, et al. Patient-related quality assurance with different combinations of treatment planning systems, techniques, and machines: A multi-institutional survey. Strahlenther Onkol. 2017;193(1):46-54.

7. Haga A, Nakagawa K, Shiraishi K, Itoh S, Terahara A, Yamashita H, Ohtomo K, Saegusa S, Imae T, Yoda K, et al. Quality assurance of volumetric modulated arc therapy using Elekta Synergy. Acta Oncol. 2009;48(8):1193-7.

8. Huang K, Bice WS Jr, Hidalgo-Salvatierra O. Characterization of an in vivo diode dosimetry system for clinical use. J Appl Clin Med Phys. 2003;4(2):132-42.

9. Mancosu P, Navarria P, Reggiori G, Cozzi L, Fogliata A, Gaudino A, Lobefalo F, Paganini L, Palumbo V, Sarina B, et al. In-vivo dosimetry with Gafchromic films for multi-isocentric VMAT irradiation of total marrow lymph-nodes: a feasibility study. Radiat Oncol. 2015;10:86.

10. Moylan R, Aland T, Kairn T. Dosimetric accuracy of Gafchromic EBT2 and EBT3 film for in vivo dosimetry. Australas Phys Eng Sci Med. 2013;36(3):331-7.

11. Lambert J, Nakano T, Law S, Elsey J, McKenzie DR, Suchowerska N. In vivo dosimeters for HDR brachytherapy: a comparison of a diamond detector, MOSFET, TLD, and scintillation detector. Med Phys. 2007;34(5):1759-65.

12. Legge K, Greer PB, O'Connor DJ, Wilton L, Richardson M, Hunter P, Wilfert A, Martin J, Rosenfeld A, Cutajar D. Real-time in vivo rectal wall dosimetry using MOSkin detectors during linac based stereotactic radiotherapy with rectal displacement. Radiat Oncol. 2017;12(1):41.

13. Petoukhova A, Russel I, Nijst-Brouwers J, van Wingerden K, van Egmond J, Jacobs D, Marinelli A, van der Sijp J, Koper P, Struikmans $H$. In vivo dosimetry with MOSFETs and GAFCHROMIC films during electron IORT for Accelerated Partial Breast Irradiation. Phys Med. 2017;44:26-33.

14. MacDougall ND, Graveling M, Hansen VN, Brownsword K, Morgan A. In vivo dosimetry in UK external beam radiotherapy: current and future usage. Br J Radiol. 2017;90(1072):20160915.

15. Gardner EA, Sumanaweera TS, Blanck O, Iwamura AK, Steel JP, Dieterich S, Maguire P. In vivo dose measurement using TLDs and MOSFET dosimeters for cardiac radiosurgery. J Appl Clin Med Phys. 
2012;13(3):3745.

16. McKeever SWS, Akselrod MS. Radiation dosimetry using pulsed optically stimulated luminescence of Al203: C. Radiat Prot Dosim. 1999;84(1-4):317-20.

17. Kim DW, Chung WK, Shin DO, Yoon M, Hwang UJ, Rah JE, Jeong H, Lee SY, Shin D, Lee SB, et al. Dose response of commercially available optically stimulated luminescent detector, $A L(2) O(3): C$ for megavoltage photons and electrons. Radiat Prot Dosim. 2012;149(2):101-8.

18. Hoshi Y, Nomura T, Oda T, Iwasaki T, Fujita K, Ishikawa T, Kato A, Ikegami T, Sakai K, Tanooka H, et al: Application of a newly developed photoluminescence glass dosimeter for measuring the absorbed dose in individual mice exposed to low-dose rate Cs-137 gamma-rays. Journal of Radiation Research 2000, 41(2):129-137.

19. Chung WK, Kim DW. Characteristic study of a radio-photoluminescence glass rod detector for clinical usages: Skin and inner body in-vivo verification. J Korean Phys Soc. 2013;62(4):670-6.

20. Lee JH, Hsu MSL,SM, Chen IJ, Chen WL, Wang CF. Dosimertry characteristics and performance comparisons: Environmental radiophotoluminescent glass dosemeters versus thermoluminescent dosemeters. Radiat Meas. 2009;44:5.

21. Nazia Neelam Shehzadi JPC, In Jung Kim, Byoung Chul Kim and Chul-Young Yi: Preliminary study on precision dosimetry using radio-photoluminescent glass dosimeters for future use in radiotherapy. Progress in Nuclear Science and Technology 2019, 6:3.

22. Tsuda M. A Few Remarks on Photoluminescence Dosimetry with High Energy X-Rays. Igaku Butsuri. 2000;20(3):131-9.

23. Corporation CT. Personal monitoring system by glass badge. 2003.

24. corporation A: RPL glass dosimeter / Small element system Dose Ace. In.; 2000.

25. Peisch E, Burgkhardt B, Vilgis M. Photoluminescence dosimetry: progress and present state of art. Radiat Prot Dosim. 1990;33:215-25.

26. Arakia F, Moribe N, Shimonobou T, Yamashita Y. Dosimetric properties of radiophotoluminescent glass rod detector in high-energy photon beams from a linear accelerator and cyber-knife. Medical physics. 2004;31(7):1980-6.

27. Hsu SM, Yeh SH, Lin MS, Chen WL. Comparison on characteristics of radiophotoluminescent glass dosemeters and thermoluminescent dosemeters. Radiat Prot Dosimetry. 2006;119(1-4):327-31.

28. KIM DW, Chung W. Characteristic study of radiophotoluminescence glass rod detector for clinical usages: skin and inner body in-vivo verification. J of Korean Phys Soc. 2013;62(3):670-6.

29. Jursinic PA. Characterization of optically stimulated luminescent dosimeters, OSLDs, for clinical dosimetric measurements. Medical physics. 2007;34(12):4594-604.

30. Jursinic PA. Changes in optically stimulated luminescent dosimeter (OSLD) dosimetric characteristics with accumulated dose. Medical physics. 2010;37(1):132-40.

31. Pedro Andreo DTB, Klaus Hohlfeld MS, Huq T, Kanai F. Laitano, Vere Smyth, Stefaan Vynckier: ABSORBED DOSE DETERMINATION IN EXTERNAL BEAM RADIOTHERAPY: An International Code of 
Practice for Dosimetry Based on Standards of Absorbed Dose to Water. In: TECHNICAL REPORTS SERIES. Edited by AGENCY IAE, vol. 398. the International Atomic Energy Agency, Wagramer Strasse 5, P.O. Box 100, A-1400 Vienna, Austria: INTERNATIONAL ATOMIC ENERGY AGENCY; 2000.

\section{Figures}

(a) Beam irradiation set up

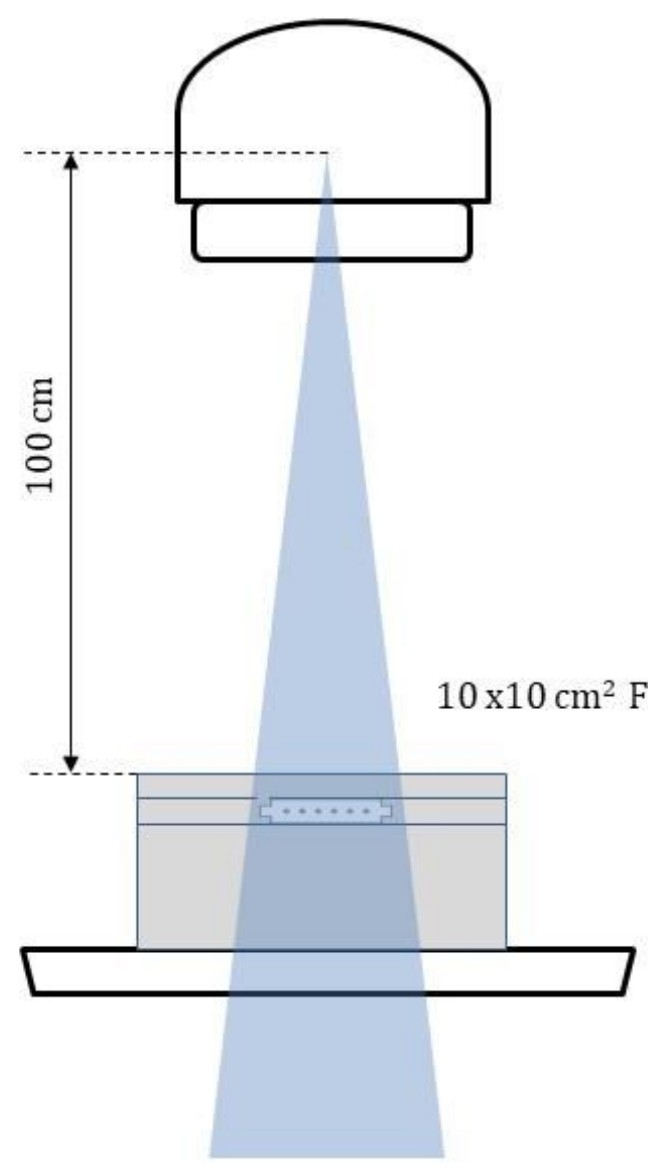

(b) RPLGD phantom
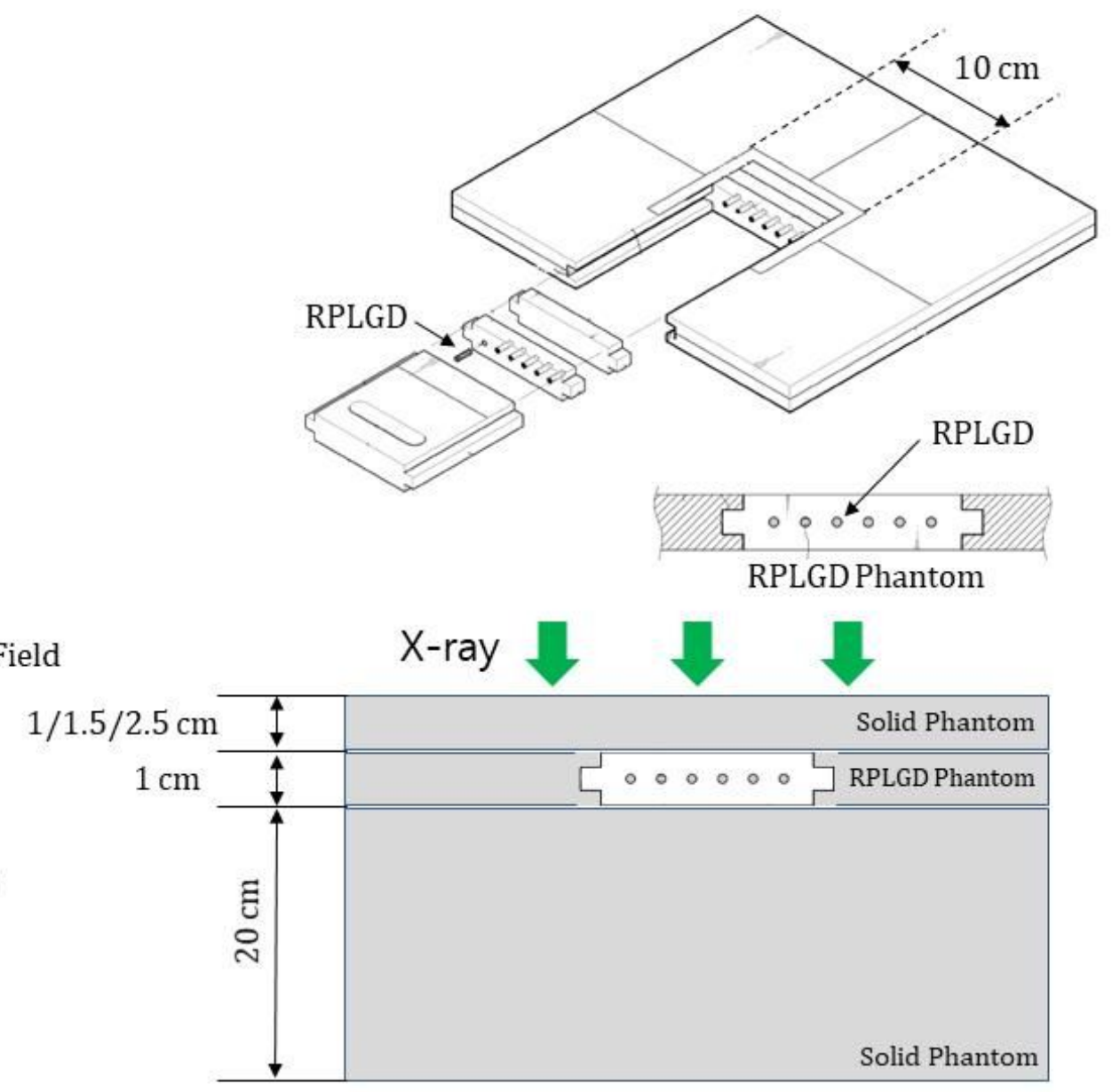

\section{Figure 1}

Measurement setup. (a) Beam irradiation setup (SSD: $100 \mathrm{~cm}$, field size: $10 \times 10 \mathrm{~cm} 2$, Depth: Dmax), (b) Homemade RPLGD phantom. 

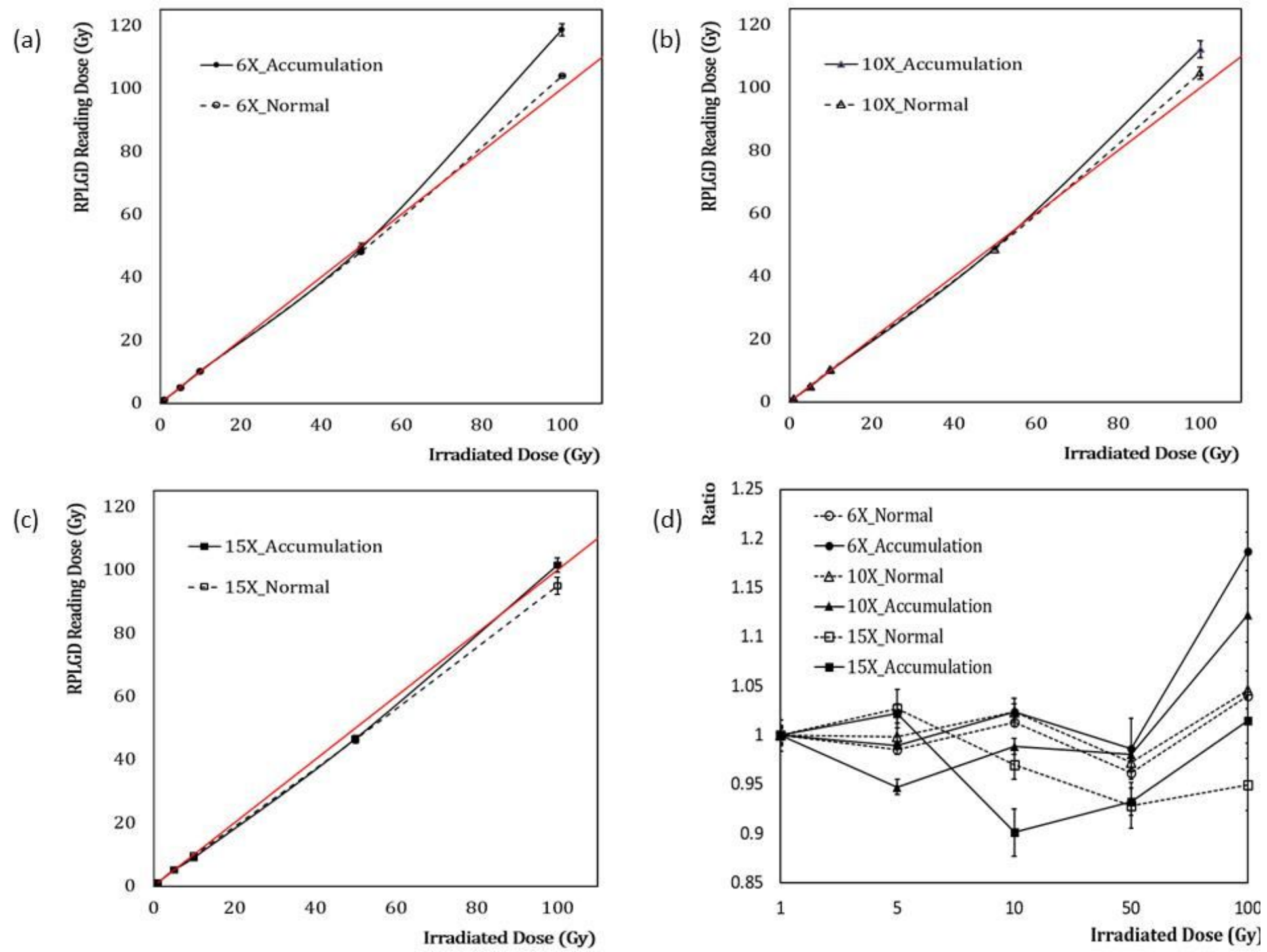

\section{Figure 2}

Measurement results for Group 1 (dashed line) and Group 2 (solid line). For each run with Group 1, the setup is annealed at $400{ }^{\circ} \mathrm{C}$ for $1 \mathrm{~h}$ before each irradiation. The annealing process is skipped for Group 2. Each group is irradiated to 1, 5, 10,50, and $100 \mathrm{~Gy}$, in order. The energies of the irradiated beam are (a) 6 MV (open circles: annealed; shaded circles: accumulated), (b) $10 \mathrm{MV}$ (open triangles: annealed; shaded triangles: accumulated), and (c) $15 \mathrm{MV}$ (open squares: annealed; shaded squares: accumulated). (d) Dose ratios of measurements and irradiation doses. 

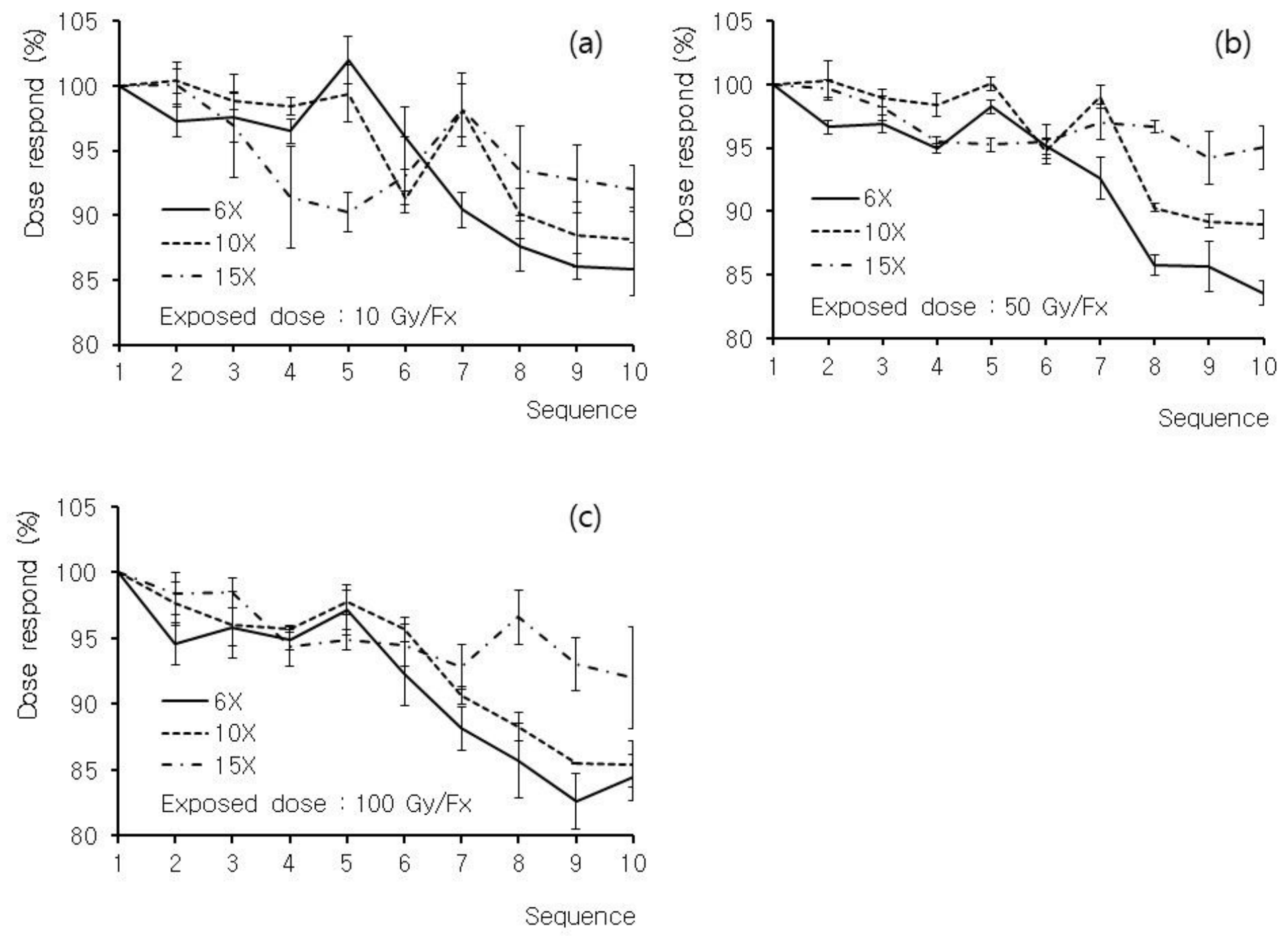

Figure 3

Measurement results for Groups 3, 4, and 5. Sensors are assumed to have been reused for similar doses over time. Groups 3, 4, and 5 are irradiated at doses of (a) 10 Gy, (b) 50 Gy, and (c) 100 Gy, respectively. Each group is irradiated with three different energies: $6 \mathrm{MV}$ (solid line), $10 \mathrm{MV}$ (dashed line), and $15 \mathrm{MV}$ (dash-dotted line). 